\title{
Eosinophilic Enteritis Confined to an Ileostomy Site
}

\author{
Bernadette U. Laxa ${ }^{\mathrm{a}}$ Alexandre Bouchard ${ }^{\mathrm{b}}$ \\ Giovanni De Petris $^{c}$ Russell Heigh ${ }^{d}$ Jacques Heppell ${ }^{b}$
}

aDepartment of Surgery, bDepartment of General Surgery and Division of Colorectal Surgery, Department of Surgery, Mayo Clinic Arizona, Phoenix, Ariz., 'Department of Laboratory Medicine/Pathology and dDivision of Gastroenterology, Department of Internal Medicine, Mayo Clinic Arizona, Scottsdale, Ariz., USA

\section{Key Words}

Eosinophilic enteritis · lleostomy · Adhesion barrier

\begin{abstract}
Eosinophilic enteritis is a rather rare condition that can manifest anywhere from esophagus to rectum. Its description in the literature is sparse, but associations have been made with collagen vascular disease, malignancy, food allergy, parasitic or viral infections, inflammatory bowel disease, and drug sensitivity. We present the case of a 41-year-old male diagnosed with ulcerative colitis who underwent proctocolectomy with ileal pouch anal anastomosis and loop ileostomy formation utilizing Seprafilm ${ }^{\circledR}$, who later developed eosinophilic enteritis of the loop ileostomy site. This is the first report of eosinophilic enteritis and its possible link to the use of bioabsorbable adhesion barriers.
\end{abstract}

\section{Introduction}

Total proctocolectomy with ileal pouch anal anastomosis is considered a standard surgical approach for diffuse, medically refractory ulcerative colitis with rectal involvement. Loop ileostomy is commonly used to divert the fecal stream, and is employed as part of a two-staged procedure, with restoration of continuity after a minimum 6 week interval. Although the rate of anastomotic dehiscence remains unaffected by defunctioning stomas, diversion of the fecal stream after ileal pouch anal anastomosis can minimize the impact of pelvic sepsis from leak, thereby significantly reducing the morbidity and mortality of these procedures [1]. However, stomal complications can occur such as high output, fistula, dermatitis, infection, bleeding, retraction, prolapse, hernia, or obstruction [2]. 
Dense peristomal adhesions can lead to abdominal pain and bowel obstruction. Adhesions can also significantly impede mobilization of the stoma at the time of closure, thereby increasing the risk of enterotomy and unplanned bowel resection, resulting in prolonged operative times [3]. In order to reduce peristomal adhesion development, many surgeons have adopted the use of adhesion barriers for placement around defunctioning stomas at the time of formation [4]. Adhesion barriers vary in form and composition and are used in a multitude of intraabdominal and pelvic procedures for general surgery and gynecologic surgery applications. The most commonly used clinically successful types include solid barriers such as sodium hyaluronate/carboxymethylcellulose film $\left(\right.$ Seprafilm $^{\circledR}$ ), oxidized regenerated cellulose (Interceed $^{\circledR}$ ), and collagen film. Other types include fluid and gel barriers composed of collagen, carboxymethylcellulose, hyaluronate, polyethylene glycol, icodextrin, as well as fibrin glue, but ultimately these have shown less efficacy in preventing adhesion formation [5-7].

Few reports in the literature describe tissue inflammatory response from the use of adhesion barriers. Eosinophilic enteritis has not been previously described in association with adhesion barrier use, however it has been observed to occur in the settings of immune, infectious, and inflammatory conditions. Giant cell foreign body reaction has been documented with the use of hyaluronate/carboxymethylcellulose film, resulting in severe adhesion formation. With the broadening application of adhesion barriers, and with the growing popularity of hyaluronate/carboxymethylcellulose film across multiple surgical fields, it is of paramount importance to report potential adverse reactions.

\section{Case Report}

A 41-year-old Caucasian male presented for surgical evaluation for medically refractory ulcerative colitis. His diagnosis was established at an outside facility at the age of 36 after presenting with initial symptoms of diarrhea and grossly bloody stools with subsequent confirmation histologically. He was first started on Asacol $800 \mathrm{mg}$ twice daily which had provided good symptomatic control for approximately 3 years. Unfortunately, the patient eventually developed recurrent symptoms of severe diarrhea with bowel movements in excess of 12 per day. Escalation therapy was attempted with Azathioprine $200 \mathrm{mg}$ daily for 3 months but was stopped due to development of pancreatitis. An 8 week course of Remicade was given without symptomatic relief. 6-Mercaptopurine was attempted but was stopped after 2 days secondary to severe abdominal pain. His history included extraintestinal manifestation of scleritis of the right eye that resolved with topical prednisone. The patient was ultimately maintained on prednisone $30-50 \mathrm{mg}$ daily for 1 year as well as Colazal $750 \mathrm{mg}$ daily for 6 months prior to his evaluation for surgery, however he continued to suffer from symptomatic ulcerative colitis.

Preoperative CT enterography showed diffuse circumferential thickening of the entire colon, with no inflammatory changes of the small bowel. He underwent laparoscopic-assisted total proctocolectomy with ileal pouch anal anastomosis and loop ileostomy, with placement of Seprafilm ${ }^{\circledR}$ on the loop ileostomy to facilitate future closure. Two months postoperatively he suffered bilateral pulmonary emboli necessitating warfarin therapy for a period of 6 months, delaying planned closure of his ileostomy. The patient noted daily episodes of minor bleeding from the ileostomy site without high output or local pain. He was found to have iron deficiency anemia and developed progressive eosinophilia without any obvious source. Stool cultures evaluating parasitic infection were negative. Adrenal insufficiency, which can manifest with eosinophilia due to the absence of glucocorticoid-induced eosinophil apoptosis, was also ruled out as an underlying cause. A review of biopsies from the colectomy performed 6 months earlier and of endoscopic biopsies of 2 years prior showed that they were without eosinophilia. At the time of ileostomy reversal 10 months later, dissection was extremely difficult due to a severe inflammatory reaction at the ileostomy site with a thickened membrane extending $10 \mathrm{~cm}$ along the bowel wall. The inflamed, indurated segment of bowel 
was resected and a hand-sewn anastomosis utilizing soft, pliable normal-appearing ileum was completed. There were no other gross intraoperative findings to suggest Crohn's disease. Following resection of the inflamed area of ileum the eosinophilia resolved, going from a peak of $17.8 \%$ (normal $0-6.6 \%$ ) to $6.4 \%$, with an absolute eosinophil count peak of $1.90 \times 10^{9} / 1$ (normal $0.0-0.4 \times 10^{9} / 1$ ) abating to $0.47 \times 10^{9} / 1$.

Gross examination revealed dense focal adhesions of serosa with edema of the mucosa and bowel wall. There were no ulcers or masses. Hematoxylin and eosin staining was performed demonstrating severe diffuse intramural eosinophilic infiltrate (defined as $\geq 40$ /high power field) extending from the subserosal to submucosal layers (fig. 1). Serosal eosinophilic exudate was also present. There was nonspecific blunting of villi with no evidence of granulomas, active neutrophilic inflammation, or intraepithelial lymphocytes. Marked edema of the submucosa was also seen.

\section{Discussion}

Eosinophilic enteritis is defined as inflammation with characteristic eosinophilic infiltration of the bowel wall in which various layers can be affected, occurring anywhere along the gastrointestinal tract from esophagus to rectum $[8,9]$. Serum eosinophilia is present in many cases. It is a relatively rare entity previously described in association with conditions such as collagen vascular disease, malignancy, food allergy, parasitic or viral infections, inflammatory bowel disease, and drug sensitivity [10-13]. Primary eosinophilic enteritis has also been described, where no precipitating factors can be identified leading to such inflammation [8]. It can present with various symptoms such as abdominal pain, protein-losing enteropathy, ulcers, ascites, obstruction, intussusception, perforation and can mimic inflammatory bowel disease [14-22]. Granulomatous formation has also been described along with eosinophilic infiltration [23]. Its association with bioresorbable membranes has not been previously described.

Seprafilm ${ }^{\circledR}$ is widely used in abdominal surgeries as a means to prevent intestinal adhesion formation [24]. It is composed of two chemically modified polysaccharides, hyaluronic acid and carboxycellulose, which are commonly found in pharmaceuticals, food and cosmetics. Upon hydration, Seprafilm ${ }^{\circledR}$ transforms into a gel-like material over the 24-48 $\mathrm{h}$ after application. The gel remains in place during the critical 7 day period when new adhesions form. It is slowly resorbed and eventually excreted from the body over an estimated 28 day period. More recently, its application has been expanded to loop ileostomy formation in which the adhesion barrier is believed to facilitate dissection of the stoma at the time of closure $[4,25]$. Complications reported that relate to bioresorbable membrane use include peritoneal inflammation, ascites, and increased leak formation when placed around an anastomosis. One notable report by David et al. described a severe inflammatory response to Seprafilm ${ }^{\circledR}$ manifested by dense adhesion formation and giant cell foreign body reaction necessitating bowel resection [26]. Some however have found these claims to be controversial. One study evaluating the effect of Seprafilm ${ }^{\circledR}$ on polymorphonuclear neutrophils, a key cellular component in the inflammatory response, found no significant influence on the overall function in polymorphonuclear neutrophils or cytokine production [27].

Our patient manifested with anemia and stomal bleed, and eosinophilia secondary to mucosal inflammation. He was also anticoagulated with warfarin, thus potentially exacerbating the stomal bleed and ultimately his anemia. One report by Chak et al. discussed a patient with chronic iron deficiency anemia and sarcoidosis being diagnosed with eosinophilic enteritis on evaluation by upper endoscopy. After treatment with 
steroids, the patient's anemia completely resolved [28]. Additional sources report favorable response of eosinophilic enteritis to steroid therapy [29]. Interestingly, our patient had been on prednisone therapy for ulcerative colitis and this was weaned in the subsequent months following colectomy. Shortly after complete discontinuation of prednisone, he was noted to develop the aforementioned symptoms of eosinophilia, anemia, and stomal bleed. The inflammatory reaction was localized to the segment of bowel forming the ileostomy and after resection of the involved portion of bowel, the patient's anemia and eosinophilia completely resolved.

\section{Conclusion}

Although Seprafilm ${ }^{\circledR}$ has generally shown utility in preventing adhesion formation after laparotomy and aids stomal closure, the sequela of eosinophilic enteritis with dense adhesion formation provides further evidence of possible paradoxical reactions to bioresorbable membrane use. Further investigation and reporting is required to fully substantiate this potentially serious but treatable condition.

\section{Disclosure Statement}

The authors have no financial disclosures or conflicts of interest. 


\begin{tabular}{r|l|l|l}
$\begin{array}{r}\text { Case Reports in } \\
\text { Gastroenterology }\end{array}$ & $\begin{array}{l}\text { Case Rep Gastroenterol 2011;5:422-427 } \\
\text { Dol: 10.1159/000329990 }\end{array}$ & $\begin{array}{l}\text { Published online: } \\
\text { August 18, 2011 }\end{array}$ & $\begin{array}{l}\text { O 2011 S. Karger AG, Basel } \\
\text { ISSN 1662-0631 } \\
\text { www.karger.com/crg }\end{array}$ \\
\hline
\end{tabular}

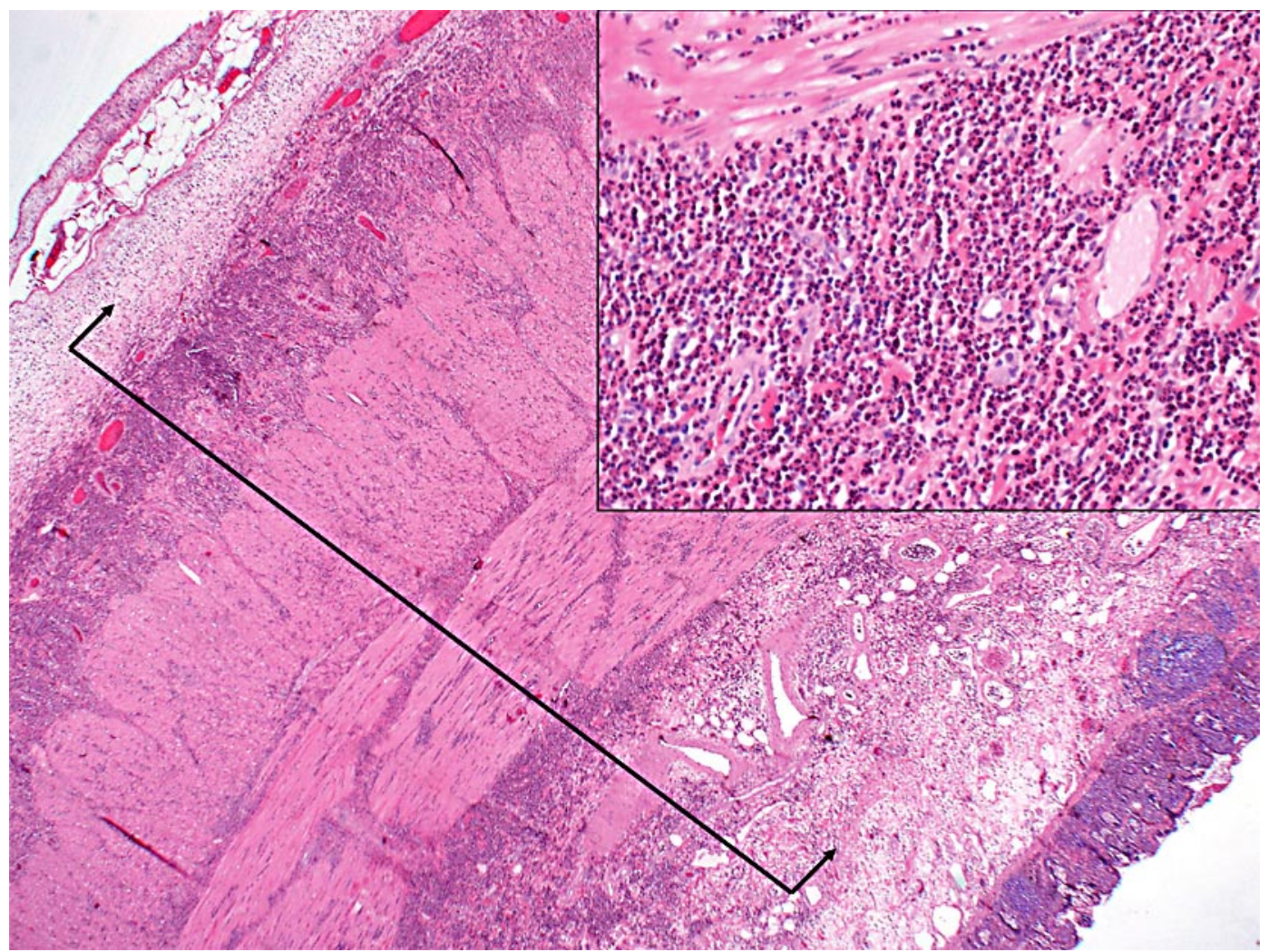

Fig. 1. Eosinophilic enteritis: microscopy with hematoxylin and eosin stain. Eosinophilic infiltrate involves the intestinal wall from the subserosa to the submucosa (line and arrows) but spares the mucosa $(20 \times)$. The inset shows a higher power view of the infiltrate of eosinophils $(200 \times)$.

\section{References}

1 Bax TW, McNevin MS: The value of diverting loop ileostomy on the high-risk colon and rectal anastomosis. Am J surg 2007;193:585-587; discussion 587-588.

$\checkmark 2$ O'Toole GC, Hyland JM, Grant DC, Barry MK: Defunctioning loop ileostomy: A prospective audit. J Am Coll Surg 1999;188:6-9.

3 Chow A, Tilney HS, Paraskeva P, Jeyarajah S, Zacharakis E, Purkayastha S: The morbidity surrounding reversal of defunctioning ileostomies: A systematic review of 48 studies including 6,107 cases. Int J Colorectal Dis 2009;24:711-723.

-4 Kawamura YJ, Kakizawa N, Tan KY, Mizokami K, Sasaki J, Tsujinaka S, Maeda T, Kuwahara Y, Konishi F: Sushi-roll wrap of Seprafilm for ileostomy limbs facilitates ileostomy closure. Tech Coloproctol 2009;13: 211-214.

5 Arnold PB, Green CW, Foresman PA, Rodeheaver GT: Evaluation of resorbable barriers for preventing surgical adhesions. Fertil Steril 2000;73:157-161.

6 Ahmad G, Duffy JM, Farquhar C, Vail A, Vandekerckhove P, Watson A, Wiseman D: Barrier agents for adhesion prevention after gynaecological surgery. Cochrane Database Syst Rev 2008;2:CD000475.

7 Ward BC, Panitch A: Abdominal adhesions: Current and novel therapies. J Surg Res 2011;165:91-111.

$\checkmark 8$ Rothenberg ME: Eosinophilic gastrointestinal disorders (EGID). J Allergy Clin Immunol 2004;113:11-28; quiz 29.

9 Dehlink E, Fiebiger E: The role of the high-affinity IgE receptor, FcepsilonRI, in eosinophilic gastrointestinal diseases. Immunol Allergy Clin North Am 2009;29:159-170, xii. 


\begin{tabular}{|c|c|c|c|}
\hline $\begin{array}{r}\text { Case Reports in } \\
\text { Gastroenterolooy }\end{array}$ & $\begin{array}{l}\text { Case Rep Gastroenterol 2011;5:422-427 } \\
\text { DOI: } 10.1159 / 000329990\end{array}$ & $\begin{array}{l}\text { Published online: } \\
\text { August 18, } 2011\end{array}$ & $\begin{array}{l}\text { () } 2011 \text { S. Karger AG, Basel } \\
\text { ISSN } 1662-0631 \\
\text { www.karger.com/crg }\end{array}$ \\
\hline
\end{tabular}

10 Sunkureddi PR, Luu N, Xiao SY, Tang WW, Baethge BA: Eosinophilic enteritis with systemic lupus erythematosus. South Med J 2005;98:1049-1052.

-11 Shakeer VK, Devi SR, Chettupuzha AP, Mustafa CP, Sandesh K, Kumar SK, Thomas V, Ashraf AS: Carbamazepine-induced eosinophilic enteritis. Indian J Gastroenterol 2002;21:114-115.

12 Montalto M, Miele L, Marcheggiano A, Santoro L, Curigliano V, Vastola M, Gasbarrini G: Anisakis infestation: A case of acute abdomen mimicking Crohn's disease and eosinophilic gastroenteritis. Dig Liver Dis 2005;37: 62-64.

13 Gonsalves N: Food allergies and eosinophilic gastrointestinal illness. Gastroenterol Clin North Am 2007;36: 75-91, vi.

14 Yun MY, Cho YU, Park IS, Choi SK, Kim SJ, Shin SH, Kim KR: Eosinophilic gastroenteritis presenting as small bowel obstruction: A case report and review of the literature. World J Gastroenterol 2007;13:1758-1760.

15 Yamada S, Chakrabandhu T, Lertprasertsuke N: Eosinophilic enteritis caused chronic partial small intestinal obstruction: A case report and review of the literature. J Med Assoc Thai 2000;83:953-958.

-16 Uenishi T, Sakata C, Tanaka S, Yamamoto T, Shuto T, Hirohashi K, Kubo S, Kinoshita H: Eosinophilic enteritis presenting as acute intestinal obstruction: A case report and review of the literature. Dig Surg 2003;20:326-329.

17 Tee HP, Swartz D, Tydd T, Leong RW: Gastrointestinal: Eosinophilic enteritis manifesting as brownpigmented duodenal ulcers. J Gastroenterol Hepatol 2009;24:1892.

18 Pungpapong S, Stark ME, Cangemi JR: Protein-losing enteropathy from eosinophilic enteritis diagnosed by wireless capsule endoscopy and double-balloon enteroscopy. Gastrointest Endosc 2007;65:917-918; discussion 918.

19 Croese J, Prociv P, Maguire EJ, Crawford AP: Eosinophilic enteritis presenting as surgical emergencies: A report of six cases. Med J Aust 1990;153:415-417.

20 Clegg-Lamptey JN, Tettey Y, Wiredu EK, Kwawukume EY: Eosinophilic enteritis - a diagnostic dilemma. West Afr J Med 2002;21:258-259.

-21 Bouhmidi A, Lorente Poyatos R, Romero Cara P, Ibanez Martin JJ, Casado Caballero F, Quintero Fuientes D, Martin Ruiz JL: Eosinophilic enteritis as a rare cause of ascites (in Spanish). Gastroenterol Hepatol 2003;26: $480-481$.

22 Biswas S, Hoo W, Katsoulas N, Munro J, Oke O: Eosinophilic enteritis: A rare cause of abdominal pain. Int J Colorectal Dis 2007;22:87-88.

23 Walia HS, Abraham TK, Walia HK: Eosinophilic enteritis with perforation. Can J Surg 1988;31:268-269.

-24 Becker JM, Dayton MT, Fazio VW, Beck DE, Stryker SJ, Wexner SD, Wolff BG, Roberts PL, Smith LE, Sweeney SA, Moore M: Prevention of postoperative abdominal adhesions by a sodium hyaluronate-based bioresorbable membrane: A prospective, randomized, double-blind multicenter study. J Am Coll Surg 1996;183:297-306.

25 Tang CL, Seow-Choen F, Fook-Chong S, Eu KW: Bioresorbable adhesion barrier facilitates early closure of the defunctioning ileostomy after rectal excision: A prospective, randomized trial. Dis Colon Rectum 2003;46: 1200-1207.

-26 David M, Sarani B, Moid F, Tabbara S, Orkin BA: Paradoxical inflammatory reaction to Seprafilm: Case report and review of the literature. South Med J 2005;98:1039-1041.

27 Otake K, Uchida K, Yoshiyama S, Inoue M, Okita Y, Watanabe H, Inoue Y, Mohri Y, Miki C, Kusunoki M: Effects of a hyaluronate-carboxymethylcellulose membrane (Seprafilm) on human polymorphonuclear neutrophil functions. J Surg Res 2008;149:243-249.

28 Chak A, Faulx A, Davessar N, Willis J: Eosinophilic enteritis. Gastrointest Endosc 2004;60:601-602.

29 Lombardi C, Salmi A, Savio A, Passalacqua G: Localized eosinophilic ileitis with mastocytosis successfully treated with oral budesonide. Allergy 2007;62:1343-1345. 